\title{
Memória oral e identidade cultural na literatura infantil e juvenil moçambicana
}

\author{
Avani Souza Silva* \\ A literatura é uma das modalidades mais ricas de sistematizar a fantasia. \\ Antonio Candido \\ Falo de milhões de homens em quem deliberadamente inculcaram o medo, o \\ complexo de inferioridade, o tremor, a prostração, o desespero, o servilismo.
}

Aimé Césaire

Neste artigo, analisamos o conto "As mãos dos pretos", do livro Nós matamos o cão tinhoso (2008), do moçambicano Luís Bernardo Honwana, publicado em Maputo em 1964. Embora não tenha sido escrito para crianças e jovens, a obra tem grande ressonância no público infantil e juvenil pela temática, espaço, personagens crianças, pelo tom de aventura, pela personagem animal, pelo cenário escolar e pela linguagem que atrai esse público leitor por sua facilidade de compreensão. A obra de Luís Bernardo Honwana é considerada até hoje um ícone da literatura moçambicana. Lida por crianças e jovens, a obra também é escolarizada em Moçambique.

Na concepção de Nelly Novaes Coelho (2000), o leitor pré-adolescente é classificado, na sua taxinomia, como "leitor crítico", que é aquele que domina completamente a leitura e exercita o pensamento crítico e reflexivo (crianças a partir dos 12/13 anos de idade, ou seja, pré-adolescentes). Lembramos que o leitor crítico está em constante formação e aprimoramento que a diversidade de textos incita.

"As mãos dos pretos" é um conto literário inspirado na tradição oral, fonte por excelência da literatura infantil e juvenil de todos os tempos. O tema central é a curiosidade de uma criança negra para saber por que as mãos dos negros têm as palmas brancas. A criança recorre à ajuda de adultos brancos que dão as respostas mais esdrúxulas possíveis, beirando a ironia e jocosidade. Câmara Cascudo (1986) relata um conto de mesma temática, recolhido no Brasil, e informa que contos semelhantes foram recolhidos na África e na Alemanha, dando o lastro da oralidade que o permeia.

Doutora em Letras pela Universidade de São Paulo (USP), São Paulo, SP, Brasil. E-mail: avanissilva@yahoo.com.br. 
O conto recolhido por Câmara Cascudo, sob o título "Por que o negro é preto", retrata exatamente a questão levantada pela criança no conto moçambicano de Luís Bernardo Honwana. Isso nos leva à seguinte questão: que o conto literário de Honwana é uma recriação elaborada a partir de um conto popular do universo moçambicano que tematiza a negritude. Honwana, a partir da motivação conhecida do porquê de as mãos dos pretos serem claras, adicionou mais elementos instigantes elaborando um conto com uma estrutura mais complexa e finalizando com uma lição de humanidade e de igualdade para colocar fim aos questionamentos sobre o preconceito racial e a busca da identidade.

A denúncia do preconceito racial e a busca da identidade que se revelam no conto fazem parte das bandeiras de luta do povo moçambicano em particular, e do povo africano em geral e, portanto, foram apropriadas pelo narrador como uma vertente do papel do intelectual desempenhado pelo autor, de que fala Edward Said: "o papel dos intelectuais deve ser o de ajudar uma comunidade nacional a sentir uma identidade comum, em um grau muito elevado" (SAID, 2005, p. 41). Um dos alicerces do pensamento do teórico palestino-americano sobre o papel do intelectual funda-se na concepção de intelectual como sendo a consciência da humanidade e pontifica: "não houve nenhuma grande revolução na história moderna sem intelectuais; de modo inverso, não houve nenhum movimento contrarrevolucionário sem intelectuais" (SAID, 2005, p. 25). Nesse sentido, ampliando esse conceito, ele pontifica que "um intelectual é um indivíduo dotado de uma vocação para representar, dar corpo e articular uma mensagem, um ponto de vista, uma atitude, filosofia ou opinião para (e também por) um público" (SAID, 2005, p. 25).

Essas considerações apontam para o fato de que o livro Nós matamos o cão tinhoso, pelas denúncias que encena, em que o colonialismo é metaforizado no cão sarnento e cheio de chagas fedorentas, constitui-se em uma intervenção política de um intelectual no status quo, servindo-se de um narrador e de uma matéria literária para sua mensagem simbólica e política, do ponto de vista da arquitetura ficcional.

Detenhamo-nos nos contos populares, haja vista a ocorrência de narrativa de mesma temática recolhida por Câmara Cascudo. Os contos populares têm determinadas características ou propriedades que explicam por que partes significativas deles ressurgem em lugares distantes do mundo, às vezes até como fragmentos de outras narrativas. Entender essas características é importante para dimensionarmos a relevência dos contos populares na formação de uma biblioteca oral a que todos podem recorrer, no fortalecimento dos laços comunitários quando eles são contados e recontadas oralmente, na preservação da memória coletiva e na constituição da identidade cultural dos povos. Sem contar, naturalmente, no enriquecimento da literatura quando os contos populares são apropriados pela escrita. Vejamos, pois, as propriedades dos contos populares. Juntamos as propriedades definidas por André Jolles (1976), Câmara Cascudo (1984) e Vladimir Propp (1984) e as sintetizamos nas seguintes: anonimato, oralidade, mobilidade, genera- 
lidade, antiguidade e permutabilidade. Todas essas características se manifestam simultaneamente.

Anonimato é a característica dos contos populares, uma vez que sua autoria é completamente desconhecida. Quando, entretanto, ele é apropriado pela escrita, neste momento passa a ter um autor que o reescreveu a partir de uma matriz oral. Oralidade é a característica que melhor se ajusta aos contos populares, pois que eles surgiram na oralidade e se mantêm nessa forma de transmissão, não obstante possam ser apropriados, e são, pela escrita. Generalidade é a propriedade que faz com que os contos sejam sempre atualizados, às vezes até modificados. A antiguidade refere-se ao nascimento dos contos e a impossibilidade de datar seu surgimento, ou mesmo definir o local em que isso teria acontecido, pois essa gênese está perdida ao longo de tempos imemoriais. A mobilidade, o próprio nome já diz, indica a capacidade que os contos populares têm de surgir em diversos lugares do mundo, sem que sua origem nem sempre possa ser determinada. Alguns contos ainda são possíveis de se determinar a região em que foram recolhidos, mas a sua origem exata perdeu-se ao longo dos tempos. Em razão dessa propriedade, é que a narrativa oral, em Moçambique, que inspirou Honwana, tem seu surgimento no Brasil, sendo recolha de Câmara Cascudo, como já mencionado acima.

A permutabilidade é a propriedade que os contos apresentam de se misturarem e de partes de um conto surgirem em outros. A permutabilidade, de acordo com a definição de Propp, decorre da propriedade principal que é a oralidade, em que os contos por serem contados oralmente modificam-se e às vezes até se interpenetram. Comum, portanto, devido à propriedade da permutabilidade, é encontrar partes de um conto formando outros contos. Interessante observar como o conto literário "As mãos dos pretos" relaciona-se com o conto popular recolhido por Câmara Cascudo. Aquele, ao que tudo indica, foi inspirado na tradição oral de Moçambique e reescrito de forma literária, criando, inclusive, outras respostas igualmente surpreendentes para a pergunta do porquê de as mãos dos negros terem as palmas brancas.

Oportuno nos lembrar que Walter Ong (1998) destaca que um repertório de temas semelhantes é encontrado na narrativa oral e em outros discursos orais em todo o mundo. Pondera ainda que "a narrativa escrita e outros discursos escritos também utilizam temas, necessariamente, mas os temas são infinitamente mais variados e menos impeditivos" (ONG, 1998, p. 32).

Nós matamos o cão tinhoso, publicado em 1964, é a segunda obra literária publicada em Moçambique, depois de Godido e outros contos, de João Dias, publicado em 1952. Essa obra dialoga com a literatura infantil e juvenil, porque, embora não tenha sido escrita especialmente para crianças e jovens, tem grande ressonância nesse segmento de leitores. Principal receptor da obra, ela trata de problemas do cotidiano de crianças na escola, apresenta personagem animal, aventuras infantis, personagens infantis, e é escrita em uma linguagem simbólica facilmente compre- 
ensível por esse público leitor, utilizando ainda termos das línguas nacionais moçambicanas, gírias e um forte apelo da oralidade.

Assim, as características da estrutura narrativa e da recepção da obra, aproximam-na da literatura infantil e juvenil. Destacamos essa aproximação especialmente nos contos "Nós matamos o cão tinhoso", "As mãos dos pretos", "Inventário de móveis e jacentes" e "Papá, cobra eu", além de excertos descritivos das machambas (roças, em ronga) e dos animais, especialmente as rolas, no conto "Nhinguitimo" (vento sul, de tempestade, em ronga). Essas considerações nos fazem incluir a obra no acervo de literatura infantil e juvenil africana de língua portuguesa.

O conto "As mãos dos pretos", analisado aqui, é dos mais emblemáticos, porque implica em identificação do leitor com a temática tratada, especialmente as crianças que se identificam imediatamente com o protagonista e sua busca por identidade. Falamos aqui em identificação, nos termos concebidos por Boaventura Souza Santos para definir identidade, tema, a nosso ver, central no conto:

As identidades culturais não são rígidas nem, muito menos, imutáveis. São resultados sempre transitórios e fugazes de processos de identificação. Mesmo as identidades aparentemente mais sólidas, como a de mulher, homem, país africano, país latino-americano ou país europeu, escondem negociações de sentido, jogos de polissemia, choques de temporalidades em constante processo de transformação, responsáveis em última instância pela sucessão de configurações hermenêuticas que de época para época dão corpo e vida a tais identidades. Identidades são, pois, identificações em curso (SANTOS, 1999, p. 119).

Tanto para o sociólogo português, Boaventura Sousa Santos, como para o antropólogo jamaicano Stuart Hall (2006), a identificação é um processo de identidade em curso, em construção, em constante transformação. Kathryn Woodward (2012) nos lembra que a ênfase na representação e no papel-chave da cultura (por exemplo, a semiótica da imagem, da publicidade, das telenovelas, dos programas de entrevistas etc.) na produção dos significados que envolvem as relações sociais levam a uma preocupação com a identificação. Esta é entendida como um processo pelo qual nós nos identificamos com os outros, baseados seja nas similaridades, seja nas diferenças que há entre nós (Woodward, 2012, p. 19). Segundo Woodward, o conceito de identificação tem sua origem na psicanálise e foi apropriado pelos estudos culturais, mais especificamente na teoria do cinema, para explicar a forte ativação de desejos inconscientes que nos aproximam e fazem com que nos vejamos na imagem ou na personagem apresentada na tela e nos identifiquemos com ela (WoODWARD, 2012, p. 19).

De acordo com Stuart Hall, dentro de nós há identidades contraditórias, empurrando em diferentes direções, de tal modo que nossas identificações estão sendo continuamente deslocadas. O próprio processo de identificação, por intermédio do qual nos projetamos em nossas identidades culturais, tornou-se mais provisório, 
variável e problemático, como lembra Hall (HALl, 2006, p. 11). Dessa forma, a identidade se apresenta como não fixa, rígida, essencial ou permanente. Hall explica: "a identidade plenamente unificada, completa, segura e coerente é uma fantasia [...]. A identidade torna-se uma celebração móvel" (HAll, 2006, p. 13). Assim, dentro de uma perspectiva teórico-crítica sobre as identidades (sejam elas nacionais ou apenas minoritárias), que rejeita percebê-las como estáveis, fixas ou permanentes, a definição de Hall de que elas são celebrações móveis ajusta-se perfeitamente.

Ademais, considerando a reflexão de Hall de que as culturas nacionais em que nascemos se constituem em uma das principais fontes de identidade cultural (HALL, 2006, p. 47), resta claro o contexto diegético da obra que, dentro das estruturas narrativas muito bem colocadas, evidenciam a formação dessa identidade cultural desde a infância. A literatura, portanto, é vetor da construção da identidade cultural.

Para o crítico brasileiro Antonio Candido, a literatura "não corrompe nem edifica, mas, trazendo livremente em si o que chamamos o bem e o que chamamos o mal, humaniza em sentido profundo, porque faz viver" (CANDIDO, 2002, p. 85). Dessa forma, no nosso entendimento, não é diferente com a literatura infantil e juvenil, na qual incluímos a obra Nós matamos o cão tinhoso, uma vez que ela também, como literatura, humaniza as crianças e jovens, promovendo a fruição e o prazer, ${ }^{1}$ e alimentando "a necessidade universal de ficção", como reconhece Candido ao analisar a importância da literatura para a formação do homem (CANDIDO, 2002, p. 8o).

A sociedade se inscreve na literatura, que, ao absorver a cultura, a história, os costumes, as tradições orais e o imaginário, fornece aos leitores instrumentos com os quais eles podem se reconhecer socialmente, em tempo e espaço. Nesse sentido, a literatura promove o fortalecimento da identidade cultural. Ainda segundo Stuart Hall, as identidades nacionais são construídas por intermédio da "narrativa da nação, tal como ela é contada nas histórias e nas literaturas nacionais, na mídia e na cultura popular (HALl, 2006, p. 52). Desse modo, o reconhecimento dessas histórias na memória coletiva e a identificação com esse conhecimento fortalecem a identidade cultural de um povo.

No conto em questão, há claramente um processo de construção identitária do negro. A criança, perguntando a diversas personagens brancas, representativas do colonialismo português, o porquê de as mãos dos pretos serem brancas, recebe como resposta as mais disparatadas explicações: ou que antigamente eles andavam de quatro, e por isso a cor das mãos e dos pés sofreram desgaste; ou porque lavavam muito as mãos; ou ainda porque deus os fez de barro e os colocou para secar, e as palmas ficaram brancas porque eles estavam pendurados num varal para secar e as palmas das mãos não tomaram sol. São muitas as explicações

Para Roland Barthes, o prazer é gozo, posse, usufruto, contentamento e é dizível, enquanto a fruição é desvanecimento (BARTHES, 2004). 
excêntricas, desmerecendo os negros e a sua cultura, revelando preconceito e racismo. As respostas, de forma genérica, que algumas personagens oferecem às indagações do menino sobre por que as mãos dos pretos não são pretas, remetem às reflexões de Frantz Fanon (2010) sobre a violência da colonização e de Albert Memmi (1977) sobre o mesmo tema, especialmente o preconceito racial que leva impiedosamente à despersonalização do colonizado e à sua coisificação.

De acordo com Albert Memmi, o colonizado mantém uma relação ambígua com o colonizador, pois um não vive sem o outro, são como faces da mesma moeda. O colonizador, no papel de opressor, o colonizado no papel de oprimido, sendo que este é desumanizado, coisificado, desprovido da humanidade para melhor ser explorado por aquele. O colonizador pasteuriza as relações com o colonizado, normalmente referindo-se a ele no plural, genericamente, utilizando-se de um pronome que substitui o nome, retirando-lhe a individualidade e coletivizandoa: "eles são preguiçosos"; "não se pode confiar neles." etc. O colonizado é, dessa forma, estigmatizado como aquele que não trabalha, cujos atributos morais são a preguiça, a falta de vontade, a ignorância, a incapacidade de aprender.

Sinal da despersonalização do colonizado: o que se poderia chamar a marca do plural. O colonizado jamais é caracterizado de maneira diferencial: só tem direito ao afogamento no coletivo anônimo: Eles são isso... Eles são todos os mesmos. [...] Se a doméstica colonizada não foi trabalhar [o colonizador] afirmará que "não se pode contar com eles" (МеммI, 1977, p. 82).

O colonizador também atribui ao colonizado a responsabilidade pela sua condição social inferior, julgando que tudo o que acontece de ruim para o colonizado é por sua culpa e incapacidade de gerir a própria vida. O colonizado, por sua vez, acata esse discurso ideológico do colonizador, introjetando-o e reproduzindo-o, culpabilizando-se a si e aos demais pela situação em que vivem todos. Não por outra razão, o menino busca a resposta dos colonizadores brancos, a propósito da constituição de seu próprio corpo, pois julga-os, como resultado do processo colonial, como seres superiores, conhecedores de uma ou mais verdades que não estão à disposição do homem comum, negro, pobre, mas de seres especiais como os colonizadores.

Para Albert Memmi, o colonizador criou uma situação tal de opressão física, moral e intelectual, que o colonizado precisa sentir-se do modo que lhe é imputado ser para poder viver e reconhecer-se como tal. Ou seja, o colonizado necessita da opressão do colonizador, e este necessita oprimir o colonizado. Um não vive sem o outro. Tanto um quanto o outro são alienados de sua própria opressão, a do colonizador que a exerce, e a do colonizado que a sofre.

Frantz Fanon (2010), estudando o processo de descolonização, relata como ele é lento, justamente para dar tempo ao colonizado de se livrar das marcas da colonização. Todavia, esse processo não é um processo tranquilo, é, sim, violento, 
pois a colonização é violenta, não tem momentos de paz. Para o psiquiatra e filósofo martinicano, todo o processo colonial é violento porque usurpa a alteridade, e todo o processo de libertação colonial é violento porque busca a retomada da alteridade. Haverá sempre disputa, pois o colonizador quer manter o status quo, ao passo que o colonizado quer rompê-lo. Os interesses, portanto, são antagônicos e daí emergem os processos violentos das lutas de libertação, de que são exemplos os países africanos, especialmente Angola e Moçambique, em que violentas guerras civis sucederam-se às guerras de libertação.

O estado de subumanidade provocado pela violência da colonização será retratado pela maioria dos contos de Nós matamos o cão tinhoso, especialmente nos seguintes: o que leva o mesmo título do livro, que é o eixo estruturador da obra, e "As mãos dos pretos", em que a criança é o porta-voz da desumanidade anunciada pelos colonos.

Quando a criança chega em casa e conta para a mãe, fazendo a mesma pergunta, ou seja, por que as mãos dos pretos são brancas, há uma brusca ruptura no ritmo da narrativa, pois a mãe começa a rir sem parar, chegando às lágrimas, fato que surpreende a criança que nunca vira alguém chorar tanto sem que tenha apanhado. Vê-se aqui uma questão cultural importante: as lágrimas estão vinculadas no imaginário infantil ao sofrimento de quem apanha. A criança não conhecia até então outra situação que provoca choro: o riso descontraído. A mãe, então, explica à criança que deus fez o homem assim, com as palmas das mãos brancas, para eles se lembrarem que todos os homens são iguais e agradecerem pelo fato de serem negros. A criança acalma sua inquietação com a explicação da mãe sobre o desejo divino de fazerem os homens iguais. É, sem dúvida, uma lição de humanidade e de igualdade dada pela mãe que a criança tem a oportunidade de aprender, não fazendo mais conta das brincadeiras e piadas dos colonialistas.

O colonialismo português impôs às colônias africanas um Estatuto do Indigenato que estipulava que os autóctones seriam considerados portugueses, com os mesmos direitos deles, desde que renunciassem à sua religião, cultura, e ao seu próprio nome. Sendo assim, muitos autóctones foram batizados com nomes portugueses, mas nunca, de fato, foram considerados portugueses, e sim portugueses de segunda categoria. A escola moçambicana, por exemplo, ensinava a geografia da metrópole e não da colônia (nomes de rios, acidentes geográficos etc.); a história que era ensinada era a história de Portugal com os seus heróis. E as línguas nacionais moçambicanas eram proibidas pelo governo colonial, de modo que as pessoas falavam línguas de um grupo de 23 delas apenas em casa, de que destacamos as seguintes: swazi, changane, sena, ronga, chuwabo, nyungwe, xope, maconde, macua.

A proibição das línguas nacionais foi mais uma das estratégias de apagamento da cultura dos povos autóctones que viviam em Moçambique e impor a língua, a cultura, a história e a religião dos colonialistas. Só após a libertação nacional, em 1975, é que a cultura de Moçambique, agora Estado, pode se expressar, livre que estava do domínio colonial português. Lembramos que nos países africanos de lín- 
gua portuguesa, a nação é anterior ao Estado. Utilizamos, neste particular, a definição dada por Benedict Anderson (1993), para quem a nação é uma comunidade politicamente imaginada e inerentemente limitada e soberana. É imaginada porque os membros de uma nação, por menor que ela seja, não conhecem todos os seus compatriotas, mas têm com eles laços comunitários simbólicos que, embora não existam concretamente, são imaginados, o que dá a unidade à ideia de nação imaginada. Ela se imagina como limitada porque suas fronteiras são finitas, e soberana porque as nações sonham em ser livres e a garantia dessa liberdade de um Estado soberano. Existe, pois, um companheiro profundo, horizontal, que caracteriza a concepção de nação de Benedict Anderson (1993, p. 25). Para Anderson, enquanto os estados nacionais são novos e históricos, as nações que lhes dão expressão política presumem sempre um passado imemorial que é compartilhado pela comunidade imaginada (ANDERson, 1993, p. 29). É por isso que, no caso dos países africanos de língua portuguesa, as nações precedem aos Estados Nacionais.

Tomando Moçambique como uma nação, sublinhamos que o Estatuto do Assimilado, imposto pela metrópole colonial nos anos 30, estabelecendo a assimilação dos africanos no ultramar português, foi um verdadeiro golpe na história e na cultura desses povos, porque, pelo estatuto, a assimilação propunha falsamente que eles passassem a ser considerados portugueses, porém de segunda classe, e para isso tinham que renunciar expressamente ao seu nome, à sua religião, aos seus costumes, à sua língua e à sua cultura, em troca de, por exemplo, poderem frequentar as escolas coloniais portuguesas e exercerem determinadas profissões, como as de enfermeiro. O Estatuto do Assimilado servia ao propósito de mostrar Portugal uno e indivisível, uma só nação, no continente e no ultramar, tentando usurpar, dessa maneira, a ideia de nação dos países africanos em que ele foi imposto.

Importante observar que na época da publicação do livro, Moçambique estava em processo de luta pela emancipação política do país do governo colonial português, e o tema do preconceito racial e do resgate da identidade nacional constituiu uma bandeira de luta importante do movimento de libertação nacional. É perfeitamente possível entender, portanto, como o conto "As mãos dos pretos" tem tanta ressonância no público infantil, que se identifica imediatamente com a personagem, justamente porque ela acende uma interrogação que possivelmente não passou na cabeça do leitor, mas que encontra eco e desperta-lhe a curiosidade de também saber a razão do porquê as mãos dos pretos serem brancas. Além disso, o conto desperta a temática da identidade, especialmente da identidade negra. Num país de negros, colonizado por brancos, convivem diferentes identidades e o conto tenta mostrar a razão por que o assunto é tratado com jocosidade pelos brancos, para perplexidade do menino.

Dessa forma, o conto é uma busca constante da identidade étnica contrapondoa, por meio da diferença, a outras identidades, no caso a identidade europeia, ou seja, do colonizador. Simultaneamente, a busca sistemática da resposta à questão é também a busca da identidade negra, moçambicana. A narrativa evidencia o pre- 
conceito e o racismo europeu em relação aos negros, culminando com um confronto sociocultural entre colonizadores e colonizados. Percebe-se no conto uma despersonalização do negro quando os brancos, inquiridos pela criança, respondem de maneira a negar a humanidade dos negros: foram feitos de barro, andavam de quatro etc. O conto é uma constante denúncia de racismo e também de busca de identidade. O narrador ao colocar a questão da identidade o faz de maneira risível, em uma sucessão de explicações cada vez mais absurdas, numa gradação que termina com as sábias palavras da mãe, recorrendo à vontade divina, o que aquieta a criança.

Notamos também que as diversas explicações sobre porque as mãos dos negros são brancas constituem novas narrativas, que se desenrolam em forma de encaixe. É como se da narrativa maior surgissem micronarrativas que impulsionassem a questão central da narrativa primeira: por que as mãos dos pretos são brancas? Esse tipo de narrativa em encaixe, em que uma estória enseja uma nova, ou ainda, que uma nova história sai da anterior, é um recurso narrativo muito utilizado nos contos populares e que agradam as crianças. Exemplo emblemático de narrativas de encaixe são "As mil e uma noites", a narrativa oral conhecida e publicada em todo o mundo. As micronarrativas então funcionariam como uma brincadeira de criança, um jogo, que termina quando um adulto amoroso, a mãe, defensora de sua identidade e da igualdade entre os homens, pontua em definitivo a questão.

Esse é mais um ponto de porque os contos populares, e aqui o conto literário em questão, têm grande ressonância no público leitor infantil e jovem, como já mencionado anteriormente. A par da construção textual que remete ao imaginário infantil, a questão central no conto é a busca da identidade, como dissemos anteriormente. Segundo Stuart Hall (2006), as identidades são múltiplas e estão em constante processo de mudança. Uma identidade fixa, imóvel, unitária é uma ilusão. Para identificar o processo de formação da identidade, Stuart Hall lembra que as partes "femininas" do eu masculino, por exemplo, constantemente negadas, permanecem com ele e encontram expressão inconsciente em muitas formas não reconhecidas na vida adulta. Assim, Hall conclui que, ao invés de falar da identidade como acabada, definitiva, deveríamos falar em identificação e concebê-la como um processo em andamento (HALL, 2006, p. 39).

Assim sendo, a identidade enquanto processo em constante construção e modificação, a evolução das micronarrativas no conto mostra exatamente o deslocamento de identidades pela qual passa o negro, aos olhos da criança, motivada pelas explicações do branco. De acordo ainda com Stuart Hall, "dentro de nós há identidades contraditórias, empurrando em diferentes direções, de tal modo que nossas identificações estão sendo continuamente deslocadas" (HALL, 2006, p. 13). Isso explica a busca da identidade empreendida pela criança, como metáfora da questão étnica. Para reafirmar a construção da identidade como um processo histórico, Hall nos lembra que a identidade é definida historicamente, e não biologicamente e que "a identidade plenamente unificada, completa, segura e coerente é uma fanta- 
sia" (HALl, 2006, p. 13). Sendo assim, estamos em constante mudança, pois a identidade é um longo processo de construção simbólica, definida historicamente por intermédio dos embates sociais de que participamos. O conto retrata esse impasse.

Por isso, a questão das mãos dos negros serem brancas é ideológica e cultural, uma vez que a identidade é definida historicamente evidenciando a igualdade entre os seres, em luta constante para defender seu espaço histórico, social e identitário. Retomando a importância dos contos populares para a preservação da memória, lembramos que quanto mais os contos são repetidos mais se fixam na oralidade e quanto mais são apropriados pela escrita, igualmente são fixados. Walter Ong (1998) lembra ainda que, a cada vez que o conto é atualizado, podendo avançar em uma direção que o fixe definitivamente pela escrita, caso em que tem uma autoria definida, ele ganha solidez, peculiaridade e unicidade, mas perde, em contrapartida, grande parte de sua mobilidade, generalidade e pluralidade. Isso porque ele está fixado na escrita, em um suporte.

Nesse sentido, o escritor ao optar em reescrever literariamente um conto popular, como aqui se verificou, está fixando o conto, dando-lhe autoria e assim também preservando a memória cultural de seu povo. São vários os estudiosos, pesquisadores, antropólogos, escritores e intelectuais de maneira geral que assumem esse papel de guardião da cultura e de preservação da memória e, consequentemente, de fortalecimento da identidade cultural de seu povo. No limite, entendemos então que o conto em questão não apenas trata da identidade individual e étnica, mas também da identidade cultural enquanto resgate da memória oral. Essas histórias transmitidas oralmente compõem não só a cultura, mas o próprio imaginário de um povo e a identidade cultural, porque como nos lembra Hall, a identidade cultural é formada pelas histórias da nação que nos são contadas.

Na definição de Gilbert Durand (2001) o imaginário é "o conjunto de imagens que constitui o capital pensado do homo sapiens, [aparecendo-lhe] como o grande denominador fundamental onde se vêm encontrar todas as criações do pensamento humano" (DURAND, 2001, p. 18). O imaginário, portanto, servindo-nos da definição de Durand, compõe-se de todo o estoque de conhecimentos, experiências e imagens que formam o patrimônio intelectual do homem. Apropriando-nos dessa definição, consideramos o universo infantil como o arcabouço de vivência, ficcional e real, que referencia o mundo infantil e o seu imaginário. Desta forma, o imaginário infantil será composto pelo conteúdo e patrimônio psíquico da criança, suas experiências, brincadeiras, jogos, cantigas, conhecimentos partilhados, afetos e a capacidade de sonhar, inventar e construir narrativas, capacidade essa, como bem frisou Antonio Candido, inerente ao homem, visível no simples fato de contar piadas, lembranças, reflexões, observações ou casos do cotidiano, por exemplo (CANDIDO, 1995, p. 242, 244).

Se, por outro lado, para Durand o imaginário é o capital pensado do homo sapiens, para Maffesoli (2001, p. 75), seu discípulo, o imaginário é que produz as imagens, sendo ele a própria cultura, e mais ainda: é a aura que reveste a cultura. Aura 
aqui tomada no sentido que lhe deu Walter Benjamin (2012). O diálogo de Nós matamos o cão tinhoso com o imaginário e universo infantis e com a própria cultura, tomando-a como sendo ela própria o imaginário e vice-versa, aproxima ainda mais a obra do acervo da literatura para crianças e jovens. Assim, ao tema, linguagem, personagens, foco narrativo, juntam-se o imaginário, o universo infantil e a própria cultura inserindo de forma inaugural, na nossa opinião, Nós matamos o cão tinhoso no acervo da literatura infantil e juvenil moçambicana. Como as imagens, presentes na cultura, formam a identidade cultural? Na medida em que nos identificamos com elas, por laços de identificação e de pertencimento. Nesse sentido, retomamos Stuart Hall que ilumina a questão das identidades culturais:

As identidades culturais são pontos de identificação, os pontos instáveis de identificação ou sutura, feitos no interior dos discursos da cultura e da história. Não uma essência, mas um posicionamento. Donde haver sempre uma política da identidade, uma política de posição, que não conta com nenhuma garantia absoluta numa "lei de origem" (HALL, 1996, p. 70).

O estudioso jamaicano, ao se debruçar sobre a questão da identidade, define a identidade cultural como aqueles "aspectos de nossas identidades que surgem de nosso 'pertencimento' a culturas étnicas, raciais, linguísticas, religiosas e, acima de tudo, nacionais" (HALl, 2006, p. 8). Também para Bauman (2005), a identidade está em constante formação e transformação, sendo por isso fluida, não fixa. Sob esse aspecto, mais se justificam os questionamentos da criança, em busca dessa identidade que para ele não estava clara, devido a sua própria idade e vulnerabilidade social. Essa situação de dúvida e inquietação da criança era cada vez mais alimentada pelos homens brancos, aguçando-lhe a curiosidade. A questão, portanto, da identidade étnica está ligada à questão da identidade cultural, porque naquela cultura da diegese do conto, o negro era um ser inferior e coisificado sob o domínio colonial.

Feitas essas considerações, focaremos o papel do intelectual representado pelo autor, na instância do narrador de Nós matamos o cão tinhoso. Para Edward Said, o intelectual é um "indivíduo dotado de uma vocação para representar, dar corpo e articular uma mensagem, um ponto de vista, uma atitude, filosofia ou opinião para um público" (SAID, 2005, p. 25). Daí decorre o papel social do intelectual que é essencialmente político: "o papel dos intelectuais é o de ajudar uma comunidade nacional a sentir uma identidade comum, e em grau muito elevado" (SAID, 2005, p. 41). Um intelectual, de acordo ainda com Said, tem que intervir socialmente apontando incoerências e injustiças, denunciando-as e propondo soluções.

Retomando o papel questionador do intelectual apontado por Edward Said, lembramos que Honwana é um intelectual que exerceu seu papel social por intermédio da literatura a par de sua inserção política em Moçambique, como deputado da Assembleia Nacional. Dessa forma, ao denunciar o racismo em consonância com a luta de libertação nacional exerceu legitimamente seu papel de intelectual, como 
postulado por Said, além de avivar a memória cultural com questões que perpassam as narrativas orais. Entendemos que o autor trouxe para a cena política excertos de uma narrativa popular de forte apelo identitário como uma denúncia do racismo que impacta a identidade cultural moçambicana. O narrador, ao dar uma solução para a questão crucial da identidade negra, reforça essa identidade e postula a igualdade entre os homens, base que inspirou as lutas de libertação nacional não só em Moçambique, mas em toda a África.

O conto "As mãos dos pretos" atualizou a memória oral, dinamizando a tradição e fortalecendo a identidade cultural. Ao dar protagonismo às crianças, trazendo a infância para dentro da literatura, o escritor mostra que o colonialismo não exime a criança de suas mazelas, manipulando-as seja para matarem o cão tinhoso, seja para destituírem sua identidade e humanidade, como no conto. Ao mesmo tempo, o autor, no âmbito da recepção, contribuiu para o fortalecimento da identidade cultural, papel do intelectual de acordo com Edward Said.

\section{Referências}

BARthes, Roland. O prazer do texto. Tradução de Jaime Guinsburg. São Paulo: Perspectiva, 4 ed. Coleção Elos, 2004.

Bauman, Zygmunt. Identidade - Entrevista a Benedetto Vecchi. Tradução de Carlos Alberto Medeiros. Rio de Janeiro: Zahar, 2005.

BENJAMIn, Walter. A obra de arte na era de sua reprodutibilidade técnica. In: Magia e técnica, arte e política: ensaios sobre literatura e história da cultura. Tradução de Sérgio Paulo Rouanet. v. 1, São Paulo: Brasiliense, 2012, p. 179-212.

CANDido, Antonio. A literatura e a formação do homem. In: Textos de Intervenção. São Paulo: Livraria Duas Cidades, Editora 34, 2002, p. 77-120.

CANDido, Antonio. Direito à literatura. In: Vários escritos. São Paulo: Duas Cidades, 1995, p. 235- 263. Cascudo, Luís da Camara. Contos tradicionais do Brasil. Rio de Janeiro/ São Paulo: Itatiaia, Edusp, 1986, p. 257-9.

CAscudo, Luís da Camara. Literatura oral no Brasil. Rio de Janeiro/São Paulo: Itatiaia, Edusp, 1984.

Durand, Gilbert. As estruturas antropológicas do imaginário. Tradução de Hélder Godinho. São Paulo: Martins Fontes, 2001.

FAnon, Franz. Os condenados da Terra. Tradução de Enilce Albergaria|Rocha e Lucy Magalhães. Juiz de Fora, Minas Gerais: UFJF, 2010.

HonwanA, Luís Bernardo. Nós matamos o cão tinhoso. Lisboa: Cotovia, 2008.

HALL, Stuart. A identidade cultural na pós-modernidade. Tradução de Tomaz Tadeu da Silva e Guacira Lopes Louro. 5. ed. Rio de Janeiro: DP\&A, 2006. 
Hall, Stuart. Identidade cultural e diáspora. In: Revista do Patrimônio Histórico e Artístico Nacional. Rio de Janeiro, IPHAN, 1996, p. 68-75.

Jolles, André. Formas simples. Tradução de Álvaro Cabral. São Paulo: Cultrix, 1976.

MAfFesoli, Michel. O imaginário é uma realidade. Entrevista realizada por Juremir Machado da Silva, Paris, 20. 03.2001. Revista FAMECOS, Porto Alegre, n. 15, agosto de 2001, p. 74-82. Disponível em: http://revistaseletronicas.pucrs.br/ojs/ index.php/revistafamecos/article/viewFile/3123/2395. Acesso em: 1 dez 2019.

Meмmi, Albert. O retrato do colonizado precedido pelo retrato do colonizador. Tradução de Roland Corbisier e Mariza Pinto Coelho. Rio de Janeiro: Paz e Terra, 1977, p. 77-84.

Novaes Coelho, Nelly. A literatura infantil. São Paulo: Moderna, 2000.

Ong, Walter. Oralidade e cultura escrita. Tradução de Enid Abreu Dobránszky. Campinas: Papirus, 1998.

Propp, Vladimir I. Morfologia do conto maravilhoso. Tradução de Jasna Paravich Sarhan. Rio de Janeiro: Forense,1984.

SAID, Edward W. Representação do intelectual: as Conferências Reith de 1993. Tradução de Milton Hatoum. São Paulo: Cia. Das Letras, 2005.

Santos, Boaventura Sousa. Pela mão de Alice. 7. ed. Porto: Afrontamento, 1999.

WoodwARD, Kathryn. Identidade e diferença: uma introdução teórica e conceitual. In: SILvA, Tomaz Tadeu da (Org.). Identidade e diferença: a perspectiva dos estudos culturais. 11. ed. Petrópolis, RJ: Vozes, 2012, p. 7-72.

Recebido em 13 de dezembro de 2019.

Aprovado em $1^{\circ}$ de março de 2020 .

\section{Resumo}

\section{Memória oral e identidade cultural na literatura infantil e juvenil moçam- bicana}

\section{Avani Souza Silva}

Com base nas noções de identidade postuladas por Stuart Hall (1996, 2003, 2006), Kathryn Woodward (2012) e Boaventura Sousa Santos (1999) e no papel do intelectual definido por Edward Said (2005), analisamos o conto "As mãos dos pretos", do livro Nós matamos o cão tinhoso, do moçambicano Luis Bernardo Honwana, publicado em 1964, em plena guerra de libertação nacional moçambicana do governo colonial português. A obra é uma constante denúncia do racismo contra a população negra e uma busca pela identidade e é considerado por nós como o marco da 
literatura infantil e juvenil moçambicana, embora não tenha sido especialmente escrito para crianças e jovens.

Palavras-chave: identidade, mãos dos pretos, Honwana, literatura infantil e juvenil, intelectual. 